OPEN ACCESS

Edited by:

Eric Ghigo,

IHU Mediterranee Infection, France

Reviewed by:

Mariella Della Chiesa,

University of Genoa, Italy

Kai Yang,

Indiana University School of

Medicine - Lafayette, United States

*Correspondence:

Georg Stary

georg.stary@meduniwien.ac.at

Specialty section

This article was submitted to

Microbes and Innate Immunity,

a section of the journal

Frontiers in Cellular and Infection

Microbiology

Received: 08 February 2020

Accepted: 16 April 2020

Published: 14 May 2020

Citation:

Stary V and Stary G (2020) NK Cell-Mediated Recall Responses:

Memory-Like, Adaptive, or

Antigen-Specific?

Front. Cell. Infect. Microbiol. 10:208

doi: 10.3389/fcimb.2020.00208

\section{NK Cell-Mediated Recall Responses: Memory-Like, Adaptive, or Antigen-Specific?}

\author{
Victoria Stary ${ }^{1}$ and Georg Stary ${ }^{2,3,4 *}$ \\ ${ }^{1}$ Department of Surgery, Medical University of Vienna, Vienna, Austria, ${ }^{2}$ Department of Dermatology, Medical University of \\ Vienna, Vienna, Austria, ${ }^{3}$ Ludwig Boltzmann Institute for Rare and Undiagnosed Diseases, Vienna, Austria, ${ }^{4}$ CeMM Research \\ Center for Molecular Medicine of the Austrian Academy of Sciences, Vienna, Austria
}

Mounting experimental evidence hints to an import role for natural killer (NK) cells in adaptive immune responses to pathogens. NK cells with adaptive features are heterogeneous and belong to different subsets according to their phenotype as well as the nature of their adaptive recall reactions. Three types of adaptive NK cell responses have been described: (i) NK cells with long-lived memory of multiple different haptens and viral antigens were described in murine liver tissue with a possible human counterpart; (ii) infection of human and mouse cytomegalovirus is associated with an expansion of $\mathrm{NKG}_{2} \mathrm{C}^{+}$and $\mathrm{Ly}_{49 \mathrm{H}^{+}} \mathrm{NK}$ cells, respectively, that selectively recognize CMV-encoded peptides thereby facilitating recall responses; (iii) cytokine-stimulated NK cells respond to different stimuli with enhanced production of IFN- $\gamma$ after re-stimulation. These exciting findings not only support the idea of NK cells with adaptive features, but define a novel field of harnessing memory NK cell subsets for therapeutic strategies.

\section{Keywords: memory NK cells, adaptive immunity, vaccine strategy, recall response, trained immunity}

\section{INTRODUCTION}

Immunological memory is a hallmark of adaptive immunity with leukocytes recognizing a previously encountered antigen and facilitating a specific and rapid immune response. Therefore, immunologic memory has the following basic characteristics: (i) enhanced response upon rechallenge to pathogens/antigens that have been encountered before and (ii) long-lived memory cells, that can persist even without the continuous presence of an antigen (Janeway et al., 2001). Immunological memory has been traditionally regarded as a unique feature of the two classical arms of the adaptive immune system, namely B cell-derived antibodies and T cells (Raff, 1973). $\mathrm{T}$ cells and $\mathrm{B}$ cells use recombinase-mediated recombination of variable gene segments (RAG) to generate a multitude of $\mathrm{T}$ and $\mathrm{B}$ cell antigen receptors (Bassing et al., 2002). Activation of the receptor by the appropriate antigen triggers clonal selection, differentiation and expansion of shortlived effector cells and long-lived memory cells. In contrast to B and T cells, all other leukocytes, including natural killer (NK) cells, do not express RAG proteins, have a limited repertoire of germline encoded receptors for the identification of target cells and are therefore considered as innate immune cells (Janeway and Medzhitov, 2002). The traditional view included that innate immune cells rapidly respond to pathogens, are critical in controlling viral infections and participate in tumor immunosurveillance in a non-specific fashion, but are unable to differentiate into memory cells (Lanier, 2005, 2007). 
The paradigm of $\mathrm{B}$ and $\mathrm{T}$ cells as the sole carriers of immunological memory has been challenged by accumulating evidence indicating that $\mathrm{NK}$ cells respond to certain antigens with features of adaptive immunity. NK cell subsets mediating recall responses are heterogeneous with diverse functional properties. They differ in their phenotype and are currently described in the literature under various terms and concepts, such as adaptive, memory, memory-like and antigen-specific NK cells. In this review we summarize and categorize the current understanding of NK cells with adaptive features.

\section{ANTIGEN-SPECIFIC NK CELL RESPONSES}

The first evidence for NK cell-associated recall responses came from mice deficient in $\mathrm{T}$ cells and $\mathrm{B}$ cells developing antigenspecific immunological memory to haptens, small molecules that form immunogenic adducts with proteins (O'Leary et al., 2006). When mice lacking $\mathrm{B}$ and $\mathrm{T}$ cells were sensitized by applying the hapten to the skin, they still developed a measurable recall response within a few days. Re-challenge with the hapten that had been applied before induced ear swelling, while application of a different hapten to sensitized mice did not induce a contact hypersensitivity reaction, indicating antigen specificity of this phenomenon (O'Leary et al., 2006). Using antibody depletion, genetic alterations and adoptive transfer of purified NK cell subsets into naïve $\mathrm{RAG}^{-/-} \gamma \mathrm{c}^{-/-}$recipients (which lack all endogenous lymphocytes, including NK cells), hapten-specific memory was identified in a subset of NK cells residing in the liver that was absent from the spleen (O'Leary et al., 2006).

So far, different groups provided accumulating evidence that murine NK cells have adaptive immune features against various structurally different haptenized proteins [2,4-dinitro-1-fluorobenzene (DNFB), 4-ethoxy-methylene2-phenyl-3-oxazalin-5-one (oxazolone) and picryl chloride] (Peng et al., 2013) as well as viral [VSV, influenza, HIV (Paust et al., 2010a), vaccinia virus (Gillard et al., 2011)] and bacterial [Salmonella typhimurium (Kupz et al., 2013)] antigens (Figure 1A).

Searching for antigen-specific memory NK cells in other species, Reeves et al. gave evidence for long-lived antigen-specific splenic and hepatic NK cells in SIV-infected rhesus macaques that lysed Gag- and Env-pulsed autologous dendritic cells compared to uninfected macaques. Blocking of the inhibitory NKG2A and activating NKG2C receptors significantly reduced antigenspecific killing, which suggested that these receptors play a role in antigen-specific target cell lysis. However, the contribution of NK cell receptors to antigen-specific responses needs to be clarified. NK cells from vaccinated animals demonstrated antigen-specific recall responses up to 5 years after vaccination (Reeves et al., 2015), indicating that antigen-specificity of NK cells might be relevant in primate species including humans.

Previous studies have long suggested that NK cell responses in humans might be antigen-specific. In HIV-1-exposed seronegative persons, increased NK cell anti-viral functions have been associated with protection (Scott-Algara et al., 2003; Ravet et al., 2007). In addition, potent NK cell responses in uninfected infants of HIV-1-positive mothers were linked with blockage of transmission in utero (Tiemessen et al., 2009), which hinted to pre-sensitization to the virus.

Subsequently, phenotypic analyses of human hepatic NK cells were suggestive for NK cell subsets similar to liver-derived NK cells in earlier animal studies (Marquardt et al., 2015; Stegmann et al., 2016). NK cells account for $\sim 30-40 \%$ of all lymphocytes in human livers compared to relatively low NK cells frequencies in the peripheral blood (5-15\%) which could be indicatory for a pool of a tissue-resident NK cell subset (Doherty et al., 1999). Human liver-resident NK cells are phenotypically different to blood-derived NK cells with increased expression of the subunit CD 49a of the $\alpha 1 \beta 1$ integrin receptor. Hepatic CD49a ${ }^{+}$NK cells resemble an immature phenotype with high expression of CD56, and low-to-absent expression of CD16 and CD57 (Marquardt et al., 2015; Stegmann et al., 2016). This is in contrast to the majority of blood NK cells that are characterized as CD56 ${ }^{\mathrm{dim}}$, $\mathrm{CD} 7^{+}, \mathrm{CD}^{+} 6^{+}$, Killer Ig-Like Receptor $(\mathrm{KIR})^{+}$cells and lack CD49a (Bjorkstrom et al., 2010). The heterogeneity of NK cell subsets is also reflected by the expression of T-box transcription factor (T-bet) and Eomesodermin (Eomes). Both transcription factors are crucial for specific developmental stages of NK cells (Gordon et al., 2012; Collins et al., 2017). NK cells isolated from human peripheral mononuclear cells are T-bet ${ }^{\text {hi }}$ and Eomes ${ }^{\text {low }}$ in spite of hepatic NK cells expressing low levels of T-bet (Knox et al., 2014; Stegmann et al., 2016). However, their function could not be directly linked to memory until a recent study demonstrated antigen-specific recall responses of NK cells in a humanized mouse model. These NK cells exhibit a phenotype similar to memory NK cells in blisters of individuals after reexposure with peptides of varicella zoster virus (Nikzad et al., 2019). The observations of this study support mouse models of antigen re-challenge suggesting liver-resident NK cells to be capable to elicit antigen-specific recall responses in effector sites such as the skin. According to a recently published study human blood-derived NK cells exhibit antigen-specific cytotoxicity upon vaccination against or infection with hepatitis B (Wijaya et al., 2020). However, it is unclear whether (i) there is a well-defined subset of NK cells that is distinct in function and phenotype and (ii) this NK cell subset originates in the liver and appears in the blood stream en route to effector sites, as proposed previously (Paust et al., 2010b). Among NK cell lineages, liverresident and skin-infiltrating NK cells appear to be highly related (Sojka et al., 2014). If liver NK cells differentiate from circulating precursor or have the ability to maintain and proliferate on site from progenitors that seeded in embryogenesis still needs to be proven (Peng et al., 2013; Cuff et al., 2016). Certain chemokine receptors have been shown to be important for homeostasis of hepatic NK cells. CXCR6 and CCR5 are mostly found on human liver NK cells and are largely absent from peripheral NK cells (Hudspeth et al., 2016; Stegmann et al., 2016). The corresponding ligands CXCL16, CCL3, and CCL5 are highly expressed by Kupffer cells, T cells, NK cells and endothelial cells on liver sinusoids (Heydtmann et al., 2005; Hudspeth et al., 2016). Additionally, hepatic CD56 ${ }^{\text {bright }} \mathrm{NK}$ cells can migrate in response to CCL3, CCL5, and CXCL16 (Hudspeth et al., 2016). However, direct proof of a liver-effector site axis and the molecular 


\section{A Antigen-specific NK cells $\quad$ B HCMV-adaptive NK cells}

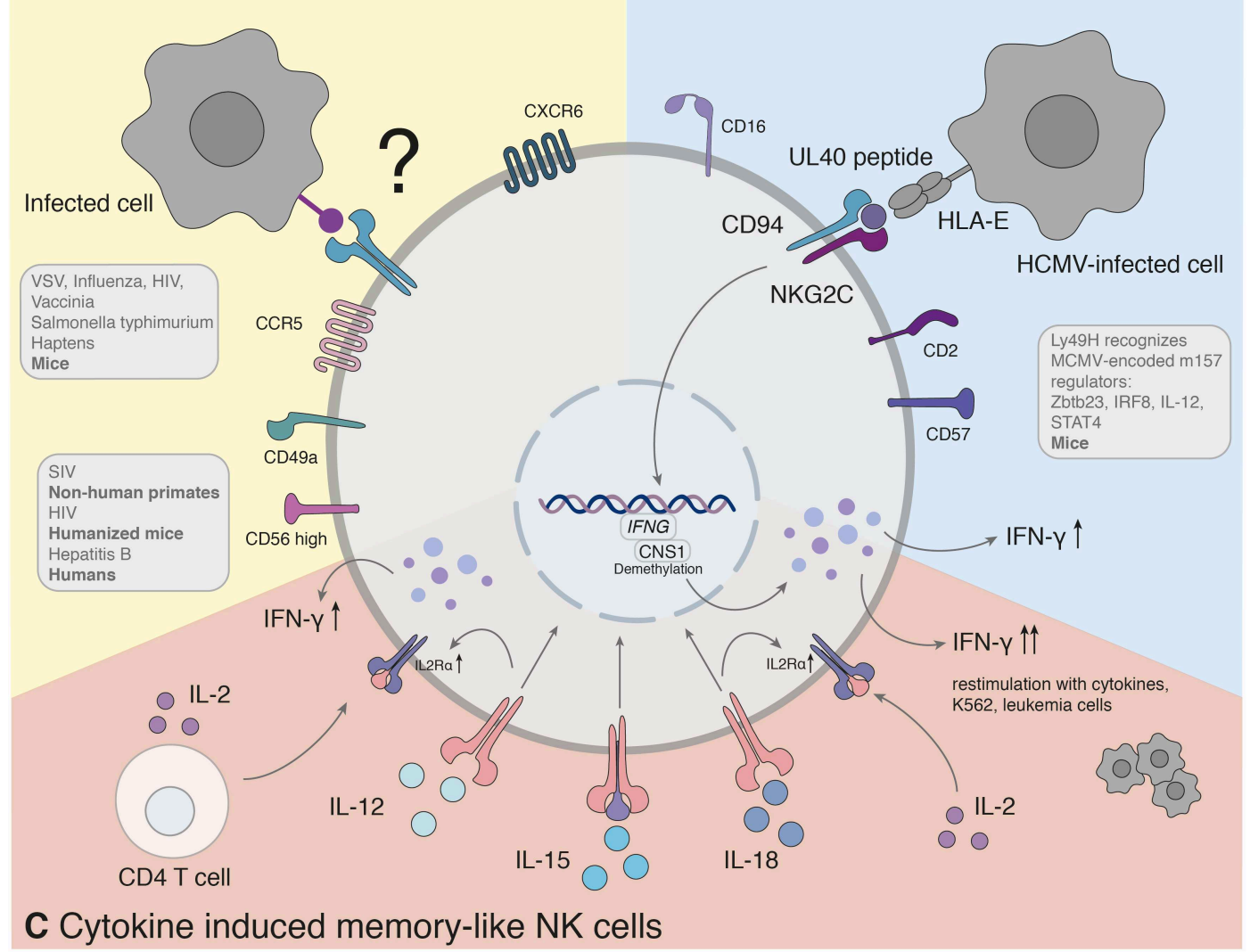

FIGURE 1 | Antigen-specific recall responses of NK cell subsets. (A) Studies hint to the presence of a human counterpart of antigen-specific NK cells. The molecular mechanism of antigen-specific NK cells has yet to be found. (B) Adaptive NK cells in response to HCMV recognize variable UL40 peptides of different HCMV strains through NKG2C/CD94. (C) Cytokine induced memory-like NK cells activated with IL-12, IL-15, and IL-18 produce significantly more IFN- $\gamma$ when re-stimulated with a non-specific stimulus. IFNG, Interferon- $\gamma$; CNS1, conserved non-coding sequence 1.

mechanism of recognition of various antigens remain to be identified.

\section{ADAPTIVE NK CELLS IN CMV INFECTION}

Recognition of target cells by NK cells is regulated through a variety of activating and inhibitory receptors. $\mathrm{Ly} 49 \mathrm{H}$ is responsible for direct recall responses and subsequent resistance of mouse cytomegalovirus infection (MCMV) in certain strains, including $\mathrm{C} 57 \mathrm{BL} / 6$ mice. As an activating receptor, $\mathrm{Ly} 49 \mathrm{H}$ can engage the MCMV-encoded cell-surface glycoprotein m157 (Brown et al., 2001; Arase et al., 2002; Smith et al., 2002) (Figure 1B). Upon infection with $\mathrm{MCMV}, \mathrm{Ly}_{4} 9 \mathrm{H}^{+} \mathrm{NK}$ cells undergo rapid clonal proliferation followed by a contraction phase, which was not observed in other viral infections (Daniels et al., 2001; Dokun et al., 2001). Adoptive transfer of $\mathrm{Ly}_{49 \mathrm{H}^{+}}$ NK cells 50 days after infection was capable to induce a robust secondary expansion und enhanced effector function upon rechallenge in naïve mice (Sun et al., 2009). The transcription factor Zbtb23 is upregulated in NK cells upon MCMV infection and crucial as regulator for the proliferation machinery of MCMV-adaptive NK cells by antagonizing the anti-proliferative factor Blimp-1 (Beaulieu et al., 2014). IL-12 receptor-deficient NK cells fail to expand after MCMV infection and do not mediate protection after re-challenge (Sun et al., 2012), indicating that proinflammatory cytokine signaling is required for the generation of adaptive NK cells toward MCMV. Subsequently, IL-12 and STAT4 promote epigenetic remodeling of the IRF8 locus and therefore upregulation of IRF8. Furthermore, IRF8 is associated with the proliferative burst of adaptive NK cells (Adams et al., 2018).

NKG2C is the human counterpart of the murine Ly49H (Sun et al., 2011) (Figure 1B). The infection of human cytomegalovirus is associated with an increased expression of HLA-E binding and activating the NK cell receptor NKG2C (Guma et al., 2004). An expansion of $\mathrm{NKG}_{2} \mathrm{C}^{+} \mathrm{NK}$ cells was observed during CMV infection (Guma et al., 2006a), similar to the response of $\mathrm{Ly}_{49 \mathrm{H}^{+}} \mathrm{NK}$ cells in MCMV. NKG2C ${ }^{+} \mathrm{NK}$ cells of CMV-seropositive donors persist at higher frequencies and exhibit enhanced activity in response to CMV reactivation compared with $\mathrm{NKG}_{2} \mathrm{C}^{+} \mathrm{NK}$ cells from seronegative donors 
(Lopez-Verges et al., 2011; Foley et al., 2012). In the case report of a 3 year-old patient with $\mathrm{T}^{-} \mathrm{B}^{+} \mathrm{NK}^{+}$severe combined immunodeficiency (SCID), $\mathrm{NKG}_{2} \mathrm{C}^{+} \mathrm{NK}$ cells were the sole provider of protective immunity against $\mathrm{CMV}$ after significant expansion of IFN- $\gamma$-producing CD16 ${ }^{+} \mathrm{CD} 94^{-} \mathrm{NKG} 2 \mathrm{C}^{+} \mathrm{NK}$ cells (Kuijpers et al., 2008). NK cells with adaptive features to HCMV have been furthermore identified in peripheral blood, liver and lung of seropositive individuals (Guma et al., 2004; Beziat et al., 2012; Marquardt et al., 2015, 2019). Notably, a similar expansion of $\mathrm{NKG}_{2} \mathrm{C}^{+} \mathrm{NK}$ cells in $\mathrm{HCMV}$-seropositive individuals has also been observed during infections with other pathogens, such as the Hantavirus (Bjorkstrom et al., 2011), HIV (Guma et al., 2006b), EBV (Saghafian-Hedengren et al., 2013) and malaria (Hart et al., 2019).

Besides NKG2C expression, HCMV-adaptive NK cells display a distinct receptor profile with a more mature and differentiated phenotype, including upregulation of CD57 and decreased expression of the inhibitory receptor NKG2A. This subset also expresses killer cell immunoglobin-like receptor (KIR) specific for self-MHC (Guma et al., 2004; Beziat et al., 2012; Schlums et al., 2015). Recent studies reveal stable alterations of transcriptional programs of HMCV-adaptive NK cells. This includes epigenetic imprint of the INFG locus, which drives IFN- $\gamma$ expression by HCMV-adaptive NK cells (Luetke-Eversloh et al., 2014). In a cohort of 196 healthy adults, HCMV seropositivity was correlated with a lack of Fce R $\gamma$, SYK, and EAT-2 expression in CD56 ${ }^{\text {dim }}$ NK cells of the peripheral blood which correlated with a downregulation of the transcription factor ZBTB16 (Zinc Finger and BTB Domain Containing 16). ZBTB16 was shown to bind the promotors of these genes (Schlums et al., 2015). Preferential expansion upon HCMV was largely confined to FcR $\gamma$-deficient NK cells in an antibody-dependent fashion (Lee et al., 2015). The mechanism of HCMV-adaptive $\mathrm{NKG}_{2} \mathrm{C}^{+} \mathrm{NK}$ cells in the blood of patients with a history of HCMV infection was ultimately proven to depend on the recognition of UL40 encoded HCMV peptides, which stabilize and load on HLA-E by NKG2C (Hammer et al., 2018; Rolle et al., 2018). Interestingly, NKG2C ${ }^{+}$ NK cells were able to differentially discriminate HCMV strains encoding for variable UL40 peptides.

There is emerging interest in the metabolic regulation of $\mathrm{NK}$ cell cytotoxicity in viral infections including adaptive immune functions. In general, naïve NK cells rely on glucose fueled by oxidative phosphorylation (Gardiner, 2019). Inhibition of glycolysis, however, decreases the clearance of MCMV-infected murine target cells by $\mathrm{Ly} 49 \mathrm{H}^{+} \mathrm{NK}$ cells indicating that NK cells require glycolysis for cytotoxicity during viral infection (Mah et al., 2017). Studies with $\mathrm{KIR}^{+}$educated blood-derived NK cells showed increased rates of glycolysis compared to uneducated NK cells even in a resting state (Pfeifer et al., 2018; Schafer et al., 2019). It was furthermore reported that CD56 $6^{\text {bright }} \mathrm{NK}$ cells express high levels of the glucose uptake receptor Glut1 and have therefore increased rates of glucose intake compared with CD56 ${ }^{\text {dim }}$ NK cells (Keating et al., 2016). The elevated glycolytic metabolism of CD56 ${ }^{\text {bright }} \mathrm{NK}$ cells would consequently support the energy demands of increased interferon-gamma (IFN- $\gamma$ ) production in the event of an immune response. In a cohort of $\mathrm{HCMV}$ seropositive individuals, $\mathrm{NKG}_{2} \mathrm{C}^{+} \mathrm{CD} 57^{+} \mathrm{NK}$ cells exhibited increased oxidative and glycolytic metabolic profiles compared to seronegative donors. Moreover, this NK cell subset of HCMV-experienced individuals also demonstrated enhanced mitochondrial membrane potential, higher expression of genes associated with the mitochondrial ATP synthase production and electron transport chain (Cichocki et al., 2018).

However, studies give hints to the existence of NKG2Cindependent pathways of $\mathrm{HCMV}$-adaptive NK cell differentiation (Muntasell et al., 2016) or emphasize a contribution of certain activating KIRs in addition to NKG2C (Beziat et al., 2012). Della Chiesa et al. studied patients with hematological malignancies after umbilical cord blood transplantation of donors carrying a homozygous deletion of the NKG2C gene. Although NKG2C was missing, they described an expansion of CD56 ${ }^{\mathrm{dim}} \mathrm{NKG} 2 \mathrm{~A}^{-} \mathrm{KIR}^{+}$ NK cells in response to CMV infection (Della Chiesa et al., 2014). These reports may be an indicator of possibly different mechanism other than $\mathrm{NKG} 2 \mathrm{C}$ being able to facilitate recall responses against $\mathrm{CMV}$.

\section{CYTOKINE-INDUCED MEMORY-LIKE NK CELLS}

In 2009, Cooper et al. demonstrated that murine NK cells activated with cytokines produce significantly more IFN- $\gamma$ when re-stimulated after up to 22 days of prior activation with IL12, IL-15, and IL-18. Pre-activated NK cells elicit an enhanced effector function against tumor cell lines. It was further shown that memory-like "trained" features are passed on to the next non-activated generation of NK cells (Cooper et al., 2009). Since the observed adaptive responses arise as a result of non-specific activation, the term cytokine-induced memory-like (CIML) NK cell was formed. CIML NK cells display some hallmarks of adaptive immunity, as they are long-lived, exhibit enhanced antitumor as well as anti-viral immune responses, and have certain epigenetic modifications.

Several features of CIML NK cells hold true for humans (summarized in Figure 1C). Analogous to NK cells of mice, human NK cells activated with cytokines were described to increase IFN- $\gamma$ production after re-stimulation with cytokines, K562, or leukemia cells (Romee et al., 2012, 2016). The mechanisms underlying the effect of these cytokines are incompletely understood. Studies of the contributions of each cytokine (IL-12, IL-15, and IL-18) demonstrated a synergistic effect in degranulation, IFN- $\gamma$, TNF- $\alpha$, and CCL3 production. At the same time IL-15 alone or in combination exhibited the highest cytotoxicity against K562 (Terren et al., 2018). The NK cell intrinsic ability for IFN- $\gamma$ production coincided with demethylation of the conserved non-coding sequence (CNS) 1 in the Ifng locus, enhancing transcription of Ifng and was additionally maintained through IL-2 production of $\mathrm{CD}^{+} \mathrm{T}$ cells (Ni et al., 2016). The enhanced NK cell proliferation and cytotoxicity of CIML NK cells arose due to a prolonged expression of IL2R $\alpha$ (CD25) resulting in a high responsiveness of IL-2 receptor stimulation (Leong et al., 2014). In addition, IL-12 and IL-18 were shown to upregulate the IL2R $\alpha$ chain sensitizing NK cells to IL-2 stimulation (Lee et al., 2012). In NK cells 
the upregulation of the mammalian target rapamycin complex 1 (mTORC1) pathway was associated with the acquisition of NK cell effector functions (Donnelly et al., 2014). IL15 and IL-18 can activate mTORC1, which plays a key role for glycolytic reprogramming and facilitated upregulation of glycolytic enzymes in NK cells (Marcais et al., 2014; Almutairi et al., 2019).

These features of CIML NK cells represent a potential approach for translational immunotherapy. CIML NK cells promoted enhanced anti-tumor activity after adoptive transfer in a melanoma xenograft model (Ni et al., 2016). Adoptive transfer of donor NK cells demonstrated to mediate graft-vs.-leukemia effects while suppressing acute graft-vs.- host disease in a murine model of allogeneic hemopoietic stem cell transplantation (Song et al., 2018). Results from a first-in-human phase 1 clinical trial with adoptively transferred CIML NK cells exhibited increased effector functions against leukemia targets leading to favorable clinical responses and remissions in a subset of AML patients (Romee et al., 2016).

\section{CONCLUSION}

The findings summarized in this review suggest that NK cells are able to fundamentally change the way they respond to later

\section{REFERENCES}

Adams, N. M., Lau, C. M., Fan, X., Rapp, M., Geary, C. D., Weizman, O. E., et al. (2018). Transcription factor IRF8 orchestrates the adaptive natural killer cell response. Immunity 48, 1172-1182 e1176. doi: 10.1016/j.immuni.2018.04.018

Almutairi, S. M., Ali, A. K., He, W., Yang, D. S., Ghorbani, P., Wang, L., et al. (2019). Interleukin-18 up-regulates amino acid transporters and facilitates amino acid-induced mTORC1 activation in natural killer cells. J. Biol. Chem. 294, 4644-4655. doi: 10.1074/jbc.RA118.005892

Arase, H., Mocarski, E. S., Campbell, A. E., Hill, A. B., and Lanier, L. L. (2002). Direct recognition of cytomegalovirus by activating and inhibitory NK cell receptors. Science 296, 1323-1326. doi: 10.1126/science.1070884

Bassing, C. H., Swat, W., and Alt, F. W. (2002). The mechanism and regulation of chromosomal V(D)J recombination. Cell 109 (Suppl.):S45-S55. doi: 10.1016/S0092-8674(02)00675-X

Beaulieu, A. M., Zawislak, C. L., Nakayama, T., and Sun, J. C. (2014). The transcription factor Zbtb32 controls the proliferative burst of virus-specific natural killer cells responding to infection. Nat. Immunol. 15, 546-553. doi: 10.1038/ni.2876

Beziat, V., Dalgard, O., Asselah, T., Halfon, P., Bedossa, P., Boudifa, A., et al. (2012). CMV drives clonal expansion of NKG2C+ NK cells expressing selfspecific KIRs in chronic hepatitis patients. Eur. J. Immunol. 42, 447-457. doi: 10.1002/eji.201141826

Bjorkstrom, N. K., Lindgren, T., Stoltz, M., Fauriat, C., Braun, M., Evander, M., et al. (2011). Rapid expansion and long-term persistence of elevated NK cell numbers in humans infected with hantavirus. J. Exp. Med. 208, 13-21. doi: 10.1084/jem.20100762

Bjorkstrom, N. K., Riese, P., Heuts, F., Andersson, S., Fauriat, C., Ivarsson, M. A., et al. (2010). Expression patterns of NKG2A, KIR, and CD57 define a process of CD56dim NK-cell differentiation uncoupled from NK-cell education. Blood 116, 3853-3864. doi: 10.1182/blood-2010-04-281675

Brown, M. G., Dokun, A. O., Heusel, J. W., Smith, H. R., Beckman, D. L., Blattenberger, E. A., et al. (2001). Vital involvement of a natural killer cell activation receptor in resistance to viral infection. Science 292, 934-937. doi: $10.1126 /$ science. 1060042 activation, resulting in features which, in certain subsets, fulfill the requirements of immunologic memory or, at least, a trained immune response. The discovery of adaptive NK cells gives rise to many questions. For instance, what are the precise mechanism of development of different subsets of NK cells? What molecular pathways underlie the specificity to a variety of antigens? Which factors drive NK cell activation, proliferation and generation of immunological memory? How are long-lived memory NK cells maintained? The paradigm shift of NK cells from classical innate killers to sophisticated immune cells possessing attributes of both entities has just begun. Further investigations into NK cell memory will have major implications in vaccination or immunotherapeutic approaches.

\section{AUTHOR CONTRIBUTIONS}

VS and GS wrote the manuscript. VS created the figure with BioRender.

\section{FUNDING}

This work was supported by the Austrian Science Fund (FWF, P30972) and the Medical Scientific Fund of the Mayor of the City of Vienna (17121).

Cichocki, F., Wu, C. Y., Zhang, B., Felices, M., Tesi, B., Tuininga, K., et al. (2018). ARID5B regulates metabolic programming in human adaptive NK cells. J. Exp. Med. 215, 2379-2395. doi: 10.1084/jem.20172168

Collins, A., Rothman, N., Liu, K., and Reiner, S. L. (2017). Eomesodermin and T-bet mark developmentally distinct human natural killer cells. JCI Insight 2:e90063. doi: 10.1172/jci.insight.90063

Cooper, M. A., Elliott, J. M., Keyel, P. A., Yang, L., Carrero, J. A., and Yokoyama, W. M. (2009). Cytokine-induced memory-like natural killer cells. Proc. Natl. Acad. Sci. U.S.A. 106, 1915-1919. doi: 10.1073/pnas.0813192106

Cuff, A. O., Robertson, F. P., Stegmann, K. A., Pallett, L. J., Maini, M. K., Davidson, B. R., et al. (2016). Eomeshi NK cells in human liver are long-lived and do not recirculate but can be replenished from the circulation. J. Immunol. 197, 4283-4291. doi: 10.4049/jimmunol.1601424

Daniels, K. A., Devora, G., Lai, W. C., O’Donnell, C. L., Bennett, M., and Welsh, R. M. (2001). Murine cytomegalovirus is regulated by a discrete subset of natural killer cells reactive with monoclonal antibody to Ly49H. J. Exp. Med. 194, 29-44. doi: 10.1084/jem.194.1.29

Della Chiesa, M., Falco, M., Bertaina, A., Muccio, L., Alicata, C., Frassoni, F., et al. (2014). Human cytomegalovirus infection promotes rapid maturation of NK cells expressing activating killer Ig-like receptor in patients transplanted with NKG2C-/- umbilical cord blood. J. Immunol. 192, 1471-1479. doi: 10.4049/jimmunol.1302053

Doherty, D. G., Norris, S., Madrigal-Estebas, L., McEntee, G., Traynor, O., Hegarty, J. E., et al. (1999). The human liver contains multiple populations of NK cells, $\mathrm{T}$ cells, and CD3+CD56+ natural T cells with distinct cytotoxic activities and Th1, Th2, and Th0 cytokine secretion patterns. J. Immunol. 163, 2314-2321.

Dokun, A. O., Kim, S., Smith, H. R., Kang, H. S., Chu, D. T., and Yokoyama, W. M. (2001). Specific and nonspecific NK cell activation during virus infection. Nat. Immunol. 2, 951-956. doi: 10.1038/ni714

Donnelly, R. P., Loftus, R. M., Keating, S. E., Liou, K. T., Biron, C. A., Gardiner, C. M., et al. (2014). mTORC1-dependent metabolic reprogramming is a prerequisite for NK cell effector function. J. Immunol. 193, 4477-4484. doi: 10.4049/jimmunol.1401558

Foley, B., Cooley, S., Verneris, M. R., Curtsinger, J., Luo, X., Waller, E. K., et al. (2012). Human cytomegalovirus (CMV)-induced memory-like NKG2C(+) 
NK cells are transplantable and expand in vivo in response to recipient CMV antigen. J. Immunol. 189, 5082-5088. doi: 10.4049/jimmunol.1201964

Gardiner, C. M. (2019). NK cell metabolism. J. Leukoc Biol. 105, 1235-1242. doi: 10.1002/JLB.MR0718-260R

Gillard, G. O., Bivas-Benita, M., Hovav, A. H., Grandpre, L. E., Panas, M. W., Seaman, M. S., et al. (2011). Thyl+ NK [corrected] cells from vaccinia virus-primed mice confer protection against vaccinia virus challenge in the absence of adaptive lymphocytes. PLoS Pathog 7:e1002141. doi: 10.1371/annotation/b29086ef-e08d-444c-8113-18a6dd429a7c

Gordon, S. M., Chaix, J., Rupp, L. J., Wu, J., Madera, S., Sun, J. C., et al. (2012). The transcription factors T-bet and Eomes control key checkpoints of natural killer cell maturation. Immunity 36, 55-67. doi: 10.1016/j.immuni.2011.11.016

Guma, M., Angulo, A., Vilches, C., Gomez-Lozano, N., Malats, N., and LopezBotet, M. (2004). Imprint of human cytomegalovirus infection on the NK cell receptor repertoire. Blood 104, 3664-3671. doi: 10.1182/blood-2004-05-2058

Guma, M., Budt, M., Saez, A., Brckalo, T., Hengel, H., Angulo, A., et al. (2006a). Expansion of CD94/NKG2C+ NK cells in response to human cytomegalovirusinfected fibroblasts. Blood 107, 3624-3631. doi: 10.1182/blood-2005-09-3682

Guma, M., Cabrera, C., Erkizia, I., Bofill, M., Clotet, B., Ruiz, L., et al. (2006b). Human cytomegalovirus infection is associated with increased proportions of NK cells that express the CD94/NKG2C receptor in aviremic HIV-1-positive patients. J. Infect. Dis. 194, 38-41. doi: 10.1086/504719

Hammer, Q., Ruckert, T., Borst, E. M., Dunst, J., Haubner, A., Durek, P., et al. (2018). Peptide-specific recognition of human cytomegalovirus strains controls adaptive natural killer cells. Nat. Immunol. 19, 453-463. doi: 10.1038/s41590-018-0082-6

Hart, G. T., Tran, T. M., Theorell, J., Schlums, H., Arora, G., Rajagopalan, S., et al. (2019). Adaptive NK cells in people exposed to Plasmodium falciparum correlate with protection from malaria. J. Exp. Med. 216, 1280-1290. doi: 10.1084 jem. 20181681

Heydtmann, M., Lalor, P. F., Eksteen, J. A., Hubscher, S. G., Briskin, M., and Adams, D. H. (2005). CXC chemokine ligand 16 promotes integrinmediated adhesion of liver-infiltrating lymphocytes to cholangiocytes and hepatocytes within the inflamed human liver. J. Immunol. 174, 1055-1062. doi: 10.4049/jimmunol.174.2.1055

Hudspeth, K., Donadon, M., Cimino, M., Pontarini, E., Tentorio, P., Preti, M., et al. (2016). Human liver-resident CD56(bright)/CD16(neg) NK cells are retained within hepatic sinusoids via the engagement of CCR5 and CXCR6 pathways. J. Autoimmun. 66, 40-50. doi: 10.1016/j.jaut.2015.08.011

Janeway, C. A., Travers, P., Walport, M., and Shlomchik, M. J. (2001). Immunobiology: The Immune System in Health and Disease, Vol 5th Edn. Garland, NY: Garland Science.

Janeway, C. A. Jr., and Medzhitov, R. (2002). Innate immune recognition. Annu. Rev. Immunol. 20, 197-216. doi: 10.1146/annurev.immunol.20.083001.084359

Keating, S. E., Zaiatz-Bittencourt, V., Loftus, R. M., Keane, C., Brennan, K., Finlay, D. K., et al. (2016). Metabolic reprogramming supports IFNgamma production by CD56bright NK cells. J. Immunol. 196, 2552-2560. doi: 10.4049/jimmunol.1501783

Knox, J. J., Cosma, G. L., Betts, M. R., and McLane, L. M. (2014). Characterization of T-bet and eomes in peripheral human immune cells. Front. Immunol. 5:217. doi: 10.3389/fimmu.2014.00217

Kuijpers, T. W., Baars, P. A., Dantin, C., van den Burg, M., van Lier, R. A., and Roosnek, E. (2008). Human NK cells can control CMV infection in the absence of T cells. Blood 112, 914-915. doi: 10.1182/blood-2008-05-157354

Kupz, A., Scott, T. A., Belz, G. T., Andrews, D. M., Greyer, M., Lew, A. M., et al. (2013). Contribution of Thy1+ NK cells to protective IFN-gamma production during Salmonella typhimurium infections. Proc. Natl. Acad. Sci. U.S.A. 110, 2252-2257. doi: 10.1073/pnas.1222047110

Lanier, L. L. (2005). NK cell recognition. Annu. Rev. Immunol. 23, 225-274. doi: 10.1146/annurev.immunol.23.021704.115526

Lanier, L. L. (2007). Back to the future-defining NK cells and T cells. Eur. J. Immunol. 37, 1424-1426. doi: 10.1002/eji.200737418

Lee, J., Zhang, T., Hwang, I., Kim, A., Nitschke, L., Kim, M., et al. (2015). Epigenetic modification and antibody-dependent expansion of memorylike NK cells in human cytomegalovirus-infected individuals. Immunity 42, 431-442. doi: 10.1016/j.immuni.2015.02.013

Lee, S. H., Fragoso, M. F., and Biron, C. A. (2012). Cutting edge: a novel mechanism bridging innate and adaptive immunity: IL- 12 induction of CD25 to form high-affinity IL-2 receptors on NK cells. J. Immunol. 189, 2712-2716. doi: 10.4049/jimmunol.1201528

Leong, J. W., Chase, J. M., Romee, R., Schneider, S. E., Sullivan, R. P., Cooper, M. A., et al. (2014). Preactivation with IL-12, IL-15, and IL-18 induces CD25 and a functional high-affinity IL-2 receptor on human cytokine-induced memory-like natural killer cells. Biol. Blood Marrow Transplant 20, 463-473. doi: 10.1016/j.bbmt.2014.01.006

Lopez-Verges, S., Milush, J. M., Schwartz, B. S., Pando, M. J., Jarjoura, J., York, V. A., et al. (2011). Expansion of a unique CD57(+)NKG2Chi natural killer cell subset during acute human cytomegalovirus infection. Proc. Natl. Acad. Sci. U.S.A. 108, 14725-14732. doi: 10.1073/pnas.1110900108

Luetke-Eversloh, M., Hammer, Q., Durek, P., Nordstrom, K., Gasparoni, G., Pink, M., et al. (2014). Human cytomegalovirus drives epigenetic imprinting of the IFNG locus in NKG2Chi natural killer cells. PLoS Pathog 10:e1004441. doi: 10.1371/journal.ppat.1004441

Mah, A. Y., Rashidi, A., Keppel, M. P., Saucier, N., Moore, E. K., Alinger, J. B., et al. (2017). Glycolytic requirement for NK cell cytotoxicity and cytomegalovirus control. JCI Insight 2:95128. doi: 10.1172/jci.insight.95128

Marcais, A., Cherfils-Vicini, J., Viant, C., Degouve, S., Viel, S., Fenis, A., et al. (2014). The metabolic checkpoint kinase mTOR is essential for IL-15 signaling during the development and activation of NK cells. Nat. Immunol. 15, 749-757. doi: $10.1038 /$ ni.2936

Marquardt, N., Beziat, V., Nystrom, S., Hengst, J., Ivarsson, M. A., Kekalainen, E., et al. (2015). Cutting edge: identification and characterization of human intrahepatic CD49a+ NK cells. J. Immunol. 194, 2467-2471. doi: 10.4049/jimmunol.1402756

Marquardt, N., Kekalainen, E., Chen, P., Lourda, M., Wilson, J. N., Scharenberg, M., et al. (2019). Unique transcriptional and protein-expression signature in human lung tissue-resident NK cells. Nat. Commun. 10:3841. doi: 10.1038/s41467-019-11632-9

Muntasell, A., Pupuleku, A., Cisneros, E., Vera, A., Moraru, M., Vilches, C., et al. (2016). Relationship of NKG2C copy number with the distribution of distinct cytomegalovirus-induced adaptive NK cell subsets. J. Immunol. 196, 3818-3827. doi: 10.4049/jimmunol.1502438

Ni, J., Holsken, O., Miller, M., Hammer, Q., Luetke-Eversloh, M., Romagnani, C., et al. (2016). Adoptively transferred natural killer cells maintain longterm antitumor activity by epigenetic imprinting and CD4(+) $\mathrm{T}$ cell help. Oncoimmunology 5:e1219009. doi: 10.1080/2162402X.2016.1219009

Nikzad, R., Angelo, L. S., Aviles-Padilla, K., Le, D. T., Singh, V. K., Bimler, L., et al. (2019). Human natural killer cells mediate adaptive immunity to viral antigens. Sci. Immunol. 4:aat8116. doi: 10.1126/sciimmunol.aat8116

O’Leary, J. G., Goodarzi, M., Drayton, D. L., and von Andrian, U. H. (2006). T celland B cell-independent adaptive immunity mediated by natural killer cells. Nat. Immunol. 7, 507-516. doi: 10.1038/ni1332

Paust, S., Gill, H. S., Wang, B. Z., Flynn, M. P., Moseman, E. A., Senman, B., et al. (2010a). Critical role for the chemokine receptor CXCR6 in NK cell-mediated antigen-specific memory of haptens and viruses. Nat. Immunol. 11, 1127-1135. doi: $10.1038 /$ ni. 1953

Paust, S., Senman, B., and von Andrian, U. H. (2010b). Adaptive immune responses mediated by natural killer cells. Immunol. Rev. 235, 286-296. doi: 10.1111/j.0105-2896.2010.00906.x

Peng, H., Jiang, X., Chen, Y., Sojka, D. K., Wei, H., Gao, X., et al. (2013). Liverresident NK cells confer adaptive immunity in skin-contact inflammation. J. Clin. Invest. 123, 1444-1456. doi: 10.1172/JCI66381

Pfeifer, C., Highton, A. J., Peine, S., Sauter, J., Schmidt, A. H., Bunders, M. J., et al. (2018). Natural killer cell education is associated with a distinct glycolytic profile. Front. Immunol. 9:3020. doi: 10.3389/fimmu.2018.03020

Raff, M. C. (1973). T and B lymphocytes and immune responses. Nature 242, 19-23. doi: 10.1038/242019a0

Ravet, S., Scott-Algara, D., Bonnet, E., Tran, H. K., Tran, T., Nguyen, N., et al. (2007). Distinctive NK-cell receptor repertoires sustain high-level constitutive NK-cell activation in HIV-exposed uninfected individuals. Blood 109, 4296-4305. doi: 10.1182/blood-2006-08-040238

Reeves, R. K., Li, H., Jost, S., Blass, E., Li, H., Schafer, J. L., et al. (2015). Antigenspecific NK cell memory in rhesus macaques. Nat. Immunol. 16, 927-932. doi: $10.1038 /$ ni.3227

Rolle, A., Meyer, M., Calderazzo, S., Jager, D., and Momburg, F. (2018). Distinct HLA-E peptide complexes modify antibody-driven effector 
functions of adaptive NK cells. Cell Rep. 24, 1967-1976 e1964. doi: 10.1016/j.celrep.2018.07.069

Romee, R., Rosario, M., Berrien-Elliott, M. M., Wagner, J. A., Jewell, B. A., Schappe, T., et al. (2016). Cytokine-induced memory-like natural killer cells exhibit enhanced responses against myeloid leukemia. Sci. Transl. Med. 8:357ra123. doi: 10.1126/scitranslmed.aaf2341

Romee, R., Schneider, S. E., Leong, J. W., Chase, J. M., Keppel, C. R., Sullivan, R. P., et al. (2012). Cytokine activation induces human memory-like NK cells. Blood 120, 4751-4760. doi: 10.1182/blood-2012-04-419283

Saghafian-Hedengren, S., Sohlberg, E., Theorell, J., Carvalho-Queiroz, C., Nagy, N., Persson, J. O., et al. (2013). Epstein-Barr virus coinfection in children boosts cytomegalovirus-induced differentiation of natural killer cells. J. Virol. 87, 13446-13455. doi: 10.1128/JVI.02382-13

Schafer, J. R., Salzillo, T. C., Chakravarti, N., Kararoudi, M. N., Trikha, P., Foltz, J. A., et al. (2019). Education-dependent activation of glycolysis promotes the cytolytic potency of licensed human natural killer cells. J. Allergy Clin. Immunol. 143, 346-358 e346. doi: 10.1016/j.jaci.2018. 06.047

Schlums, H., Cichocki, F., Tesi, B., Theorell, J., Beziat, V., Holmes, T. D., et al. (2015). Cytomegalovirus infection drives adaptive epigenetic diversification of NK cells with altered signaling and effector function. Immunity 42, 443-456. doi: 10.1016/j.immuni.2015.02.008

Scott-Algara, D., Truong, L. X., Versmisse, P., David, A., Luong, T. T., Nguyen, N. V., et al. (2003). Cutting edge: increased NK cell activity in HIV-1-exposed but uninfected Vietnamese intravascular drug users. J. Immunol. 171, 5663-5667. doi: 10.4049/jimmunol.171.11.5663

Smith, H. R., Heusel, J. W., Mehta, I. K., Kim, S., Dorner, B. G., Naidenko, O. V., et al. (2002). Recognition of a virus-encoded ligand by a natural killer cell activation receptor. Proc. Natl. Acad. Sci. U.S.A. 99, 8826-8831. doi: 10.1073/pnas.092258599

Sojka, D. K., Plougastel-Douglas, B., Yang, L., Pak-Wittel, M. A., Artyomov, M. N., Ivanova, Y., et al. (2014). Tissue-resident natural killer (NK) cells are cell lineages distinct from thymic and conventional splenic NK cells. Elife 3:e01659. doi: 10.7554/eLife.01659.015

Song, Y., Hu, B., Liu, Y., Jin, Z., Zhang, Y., Lin, D., et al. (2018). IL-12/IL18-preactivated donor NK cells enhance GVL effects and mitigate GvHD after allogeneic hematopoietic stem cell transplantation. Eur. J. Immunol. 48, 670-682. doi: 10.1002/eji.201747177
Stegmann, K. A., Robertson, F., Hansi, N., Gill, U., Pallant, C., Christophides, T., et al. (2016). CXCR6 marks a novel subset of T-bet(lo)Eomes(hi) natural killer cells residing in human liver. Sci. Rep. 6:26157. doi: 10.1038/srep 26157

Sun, J. C., Beilke, J. N., and Lanier, L. L. (2009). Adaptive immune features of natural killer cells. Nature 457, 557-561. doi: 10.1038/nature 07665

Sun, J. C., Lopez-Verges, S., Kim, C. C., DeRisi, J. L., and Lanier, L. L. (2011). NK cells and immune "memory". J. Immunol. 186, 1891-1897. doi: 10.4049/jimmunol.1003035

Sun, J. C., Madera, S., Bezman, N. A., Beilke, J. N., Kaplan, M. H., and Lanier, L. L. (2012). Proinflammatory cytokine signaling required for the generation of natural killer cell memory. J. Exp. Med. 209, 947-954. doi: 10.1084 /jem.20111760

Terren, I., Mikelez, I., Odriozola, I., Gredilla, A., Gonzalez, J., Orrantia, A., et al. (2018). Implication of interleukin-12/15/18 and ruxolitinib in the phenotype, proliferation, and polyfunctionality of human cytokine-preactivated natural killer cells. Front. Immunol. 9:737. doi: 10.3389/fimmu.2018.00737

Tiemessen, C. T., Shalekoff, S., Meddows-Taylor, S., Schramm, D. B., Papathanasopoulos, M. A., Gray, G. E., et al. (2009). Cutting edge: unusual NK cell responses to HIV-1 peptides are associated with protection against maternal-infant transmission of HIV-1. J. Immunol. 182, 5914-5918. doi: 10.4049/jimmunol.0900419

Wijaya, R. S., Read, S. A., Truong, N. R., Han, S., Chen, D., Shahidipour, H., et al. (2020). HBV vaccination and HBV infection induces HBV-specific natural killer cell memory. Gut. doi: 10.1136/gutjnl-2019-319252. [Epub ahead of print].

Conflict of Interest: The authors declare that the research was conducted in the absence of any commercial or financial relationships that could be construed as a potential conflict of interest.

Copyright (C) 2020 Stary and Stary. This is an open-access article distributed under the terms of the Creative Commons Attribution License (CC BY). The use, distribution or reproduction in other forums is permitted, provided the original author(s) and the copyright owner(s) are credited and that the original publication in this journal is cited, in accordance with accepted academic practice. No use, distribution or reproduction is permitted which does not comply with these terms. 